\title{
Using the damage from 2010 Haiti earthquake for calibrating vulnerability models of typical structures in Port-au-Prince (Haiti)
}

\author{
S. Molina - Y. Torres • B. Benito • M. Navarro • \\ D. Belizaire
}

Received: 7 May 2013 / Accepted: 23 November 2013

C) Springer Science+Business Media Dordrecht 2013

\begin{abstract}
After the 2010 Haiti earthquake, that hits the city of Port-au-Prince, capital city of Haiti, a multidisciplinary working group of specialists (seismologist, geologists, engineers and architects) from different Spanish Universities and also from Haiti, joined effort under the SISMO-HAITI project (financed by the Universidad Politecnica de Madrid), with an objective: Evaluation of seismic hazard and risk in Haiti and its application to the seismic design, urban planning, emergency and resource management. In this paper, as a first step for a structural damage estimation of future earthquakes in the country, a calibration of damage functions has been carried out by means of a two-stage procedure. After compiling a database with observed damage in the city after the earthquake, the exposure model (building stock) has been classified and through an iteratively two-step calibration process, a specific set of damage functions for the country has been proposed. Additionally, Next Generation Attenuation Models (NGA) and $\mathrm{Vs}^{30}$ models have been analysed to choose the most appropriate for the seismic risk estimation in the city. Finally in a next paper, these functions will be used to estimate a seismic risk scenario for a future earthquake.
\end{abstract}

S. Molina $(\bowtie)$

Facultad de Ciencias, Universidad de Alicante, Alicante, Spain e-mail: sergio.molina@ua.es

Y. Torres · B. Benito

ETSI Topografía, Geodesia y Cartografía, Universidad Politécnica de Madrid,

Madrid, Spain

e-mail: y.torres@upm.es

B. Benito

e-mail: mariabelen.benito@upm.es

\section{Navarro}

Facultad de Ciencias, Universidad de Almería, Almería, Spain

e-mail: mnavarro@ual.es

D. Belizaire

Observatoire National de l'Enviroment et de la Vulnerabilite (ONEV),

Ministere de l'Environnement Haitien, Port-au-Prince, Haiti

e-mail: bdwynn1@gmail.com 
Keywords Damage Functions · Vulnerability - Seismic risk - Microzonation ·

NGA models

\section{Introduction}

On the 12th January 2010, an earthquake hit Port-au-Prince, capital city of Haiti. The earthquake reached a magnitude Mw 7.0 and the epicentre was located near the town of Léogâne, approximately $25 \mathrm{~km}$ west of Port-au-Prince (Calais et al. 2010).

The earthquake occurred in the boundary region separating the Caribbean plate and the North American plate. This plate boundary is dominated by left-lateral strike slip motion and compression, and accommodates about $20 \mathrm{~mm} / \mathrm{y}$ slip, with the Caribbean plate moving eastward with respect to the North American plate (DeMets et al. 2000). Initially, the location and focal mechanism of the earthquake seemed to involve straightforward accommodation of oblique relative motion between the Caribbean and North American plates along the Enriquillo-Plantain Garden fault system (EPGFZ). However, Hayes et al. (2010) combined seismological observations, geologic field data, and space geodetic measurements to show that, instead, the rupture process involved slip on multiple faults. Besides, the authors showed that remaining shallow shear strain will be released in future surface-rupturing earthquakes on the EPGFZ. Calais et al. (2010) obtained a source mechanism implying that $62 \%$ of the moment release occurred by strike-slip motion and $38 \%$ by reverse dip-slip motion. Best-fit fault strike was estimated as N78E, slightly more north-directed than the Enriquillo-Plantain Garden fault (N85E) and dipping $70^{\circ}$ to the north.

In December 2010, a Spanish cooperation project-SISMO-HAITI-financed by the Universidad Politécnica de Madrid, started with an objective: Evaluation of seismic hazard and risk in Haiti and its application to the seismic design, urban planning, emergency and resource management. Surveys of earthquake effects, dedicated to damage appraisal, have remarked a great variability in the buildings performance during the Haiti earthquake. A variability of the ground motion could have been remarked too if more earthquake records had been collected. In front of these variability, our task is to provide a probabilistic measure of the expected damage in the site, in a given time duration. The study is partitioned into specific sections: seismic hazard, exposure, vulnerability and assets, according to a widespread literature devoted to risk analysis.

The study has been carried out during 2011-2012 by a multidisciplinary working group of specialists in every part of the project (seismologist, geologists, engineers and architects) from different Spanish Universities and also from Haiti. In this paper, as a first step for a structural damage estimation of future earthquakes in the country, a calibration of damage functions has been carried out by means of a two-stage procedure. In a next paper, these functions will be used to estimate a seismic risk scenario for a future earthquake.

\section{Vulnerability and risk in Haiti}

In general, risk is defined as the expected physical damage and the connected losses that are computed from the convolution of probability of occurrence of hazardous events and the vulnerability of the exposed elements to a certain hazard (United Nations Disaster Relief Organization). According to McGuire (2004), seismic risk entails a set of events (earthquakes likely to happen), the associated consequences (damage and loss in the broadest sense), and the associated probabilities of occurrence (or exceedance) over a defined time period. Thus, 
seismic risk can be expressed as the combination of seismic hazard, exposure, vulnerability and economic and social losses involved.

For a deterministic analysis, the seismic hazard refers to the shaking effects at a certain site caused by a scenario earthquake. While the term exposure represents the availability and inventory of buildings, infrastructure facilities and people in the respective study area subjected to a certain seismic event, structural (i.e., physical) vulnerability stands for the susceptibility of each individual element (building, infrastructure, etc.) to suffer damage given the level of earthquake shaking. This results in structural (and non-structural) damages, which directly implicate economic losses as well as casualties.

After the 2010 Haiti earthquake, many authors have published papers analysing the building stock of the country, i.e. the exposure of the country, and its vulnerability.

DesRoches et al. (2011) carried out a detailed description of the damage due to the 2010 Haiti earthquake. They analysed the building typologies using a database provided by the IHSI (Institut haïtien de statistique et d'informatique, 2010) and provided a damage and losses estimation (assessing that the event can certainly be classified as a major catastropheperhaps the worst in modern history).

Goodno et al. (2011) analysed the damage suffered by the non-structural elements in selected critical facilities, mainly those related to electric systems. They concluded that that many critical institutions in Haiti did not utilize state-of-the-art engineering design or construction practices when installing non-structural equipment that turned out to be crucial to their post-earthquake operations.

Holliday and Grant (2011) described the building behaviour of the buildings at the Christianville district, located $8 \mathrm{~km}$ east of Léogâne and near the epicenter of the 12 January. Within that district it exists a grouping of buildings constructed in the last 40 years using Haitian constructive methods. They observed a great variability in the performance of these buildings during the earthquake - some buildings completely collapsed, while others survived without a crack. They provided an analysis of the buildings on the site from various perspectives, including earthquake survivability, construction techniques, structural details, and changes that could be made to improve survivability in the future and the issues involved in a new adaptable building design.

Mix et al. (2011) sought to determine the failure modes for residential housing in the area and surveyed the structural systems, construction materials, building practices, and nonengineering constraints that dictate these practices. They concluded that the most of the damage was due to inadequate seismic detailing of reinforced concrete elements, deficient materials and construction practices, and lack of seismic considerations in the design of structural systems with sufficient lateral interconnectivity.

Marshall et al. (2011) observed that residential buildings in Haiti are typically constructed by their owners, who may or may not have the skills or resources to build a structure that is earthquake-safe. They conclude that few structures are designed by engineering professionals or are inspected for quality of construction and that the two most common construction materials are low strength and quality masonry block and reinforced concrete.

Lang and Marshall (2011) concluded that infilled frame systems performed poorly and account for the majority of structural collapses. Buildings assembled in a manner similar to confined masonry, however, performed well and experienced little damage. Damage assessments conducted around Port-au-Prince reveal that $20 \%$ of the housing stock was completely destroyed and $27 \%$ was significantly damaged.

O'Brien et al. (2011) compared the observed damage in reinforced concrete buildings with results from a similar survey done after the 1999 earthquakes near Düzce, Turkey. They concluded that the frequency of damage in RC buildings was higher in Haiti than in Turkey. 
In general, two approaches are available for the representation of the ground motion in the estimation of earthquake damage suffered by a certain building type. On one hand, the traditional approach based on empirical parameters such as macroseismic intensity or peak ground acceleration to represent seismic ground motion; on the other hand, the more recent analytical approach uses the entire response spectra preferably in the spectral accelerationspectral displacement domain (Crowley et al. 2004). The capacity spectrum method (CSM) is applied to iteratively compute the buildings inelastic lateral spectral displacement demand $\mathrm{Sd}$, which is a measure of damage extent.

In order to compute estimated damage to the exposure of a city some tools have been developed in the last years: HAZUS-MH (FEMA 2008), LNECLOSS (Campos Costa et al. 2006), SELENA (Molina et al. 2010), among others. Those tools need the exposure to be represented by a set of damage functions (capacity and fragility curves that are usually obtained through push-over analysis).

The main goal of this paper is to develop Haitian specific damage functions related to the current exposure through an iterative calibration process using the damage after that 2010 Haiti earthquake. In order to compute the theoretical damage probability that will be compared with the observed probabilities, the analytical risk and loss assessment tool SELENA is applied (Molina et al. 2010). In SELENA, three user-selectable methods are incorporated to compute the damage estimates: the traditional capacity spectrum method as proposed by ATC-40 (ATC 1996), a recent modification called the Modified Acceleration Displacement Response Spectra (MADRS) method, and the improved displacement coefficient method IDCM (both FEMA-440, ATC 2005). For the present study, the MADRS procedure is applied.

\section{Two-stage procedure for vulnerability calibration}

To apply any of the available capacity spectrum methods, both seismic demand and the capacity curve have to be transformed into the spectral acceleration-spectral displacement $\left(S_{a}-S_{d}\right)$ domain (Fig. 1a). The capacity curve will be represented by the yield point $\left(d_{y},-\right.$ displacement and $\mathrm{a}_{\mathrm{y}}$-acceleration), the ultimate point ( $\mathrm{d}_{\mathrm{u}}$-displacement and $\mathrm{a}_{\mathrm{u}}$-acceleration) and the ductility $(\mu)$. Thereby, seismic demand is represented by the elastic response spectrum while the capacity curve reflects the building's lateral displacement $\delta$ as a function of a horizontal force V applied to the structure. Beside a number of factors, building capacity curves mainly depend on the building type (working materials and construction), number of stories (height), and also from its region reflecting local building regulations as well as local construction practice and quality.

The main task of the capacity-spectrum method is to find that point on the capacity curve consistent with the seismic demand being reduced for nonlinear effects. Since each point on the capacity curve represents a certain state of structural damage and thus reflects an increase in structural damping as the damages accumulate, the performance point will be found iteratively. As Fig. 1a illustrates, the performance point finally is characterized by a spectral acceleration $a_{p}$ and spectral displacement $d_{p}$ (and establishing the basis for assigning discrete damage probabilities P).

Once the performance point and its corresponding spectral displacement $d_{p}$ are found, structural vulnerability (fragility) functions for each damage state $d_{s}$ are required to assign damage probabilities $P\left[d_{s} \mid d_{p}\right]$. These represent cumulative probabilities of a certain building type of being in or exceeding one of the different damage states $d_{s}$ dependent on spectral displacement $S_{d}$. We have used the lognormal cumulative probability function (Eq. 1) given by HAZUS (FEMA, 2008). 


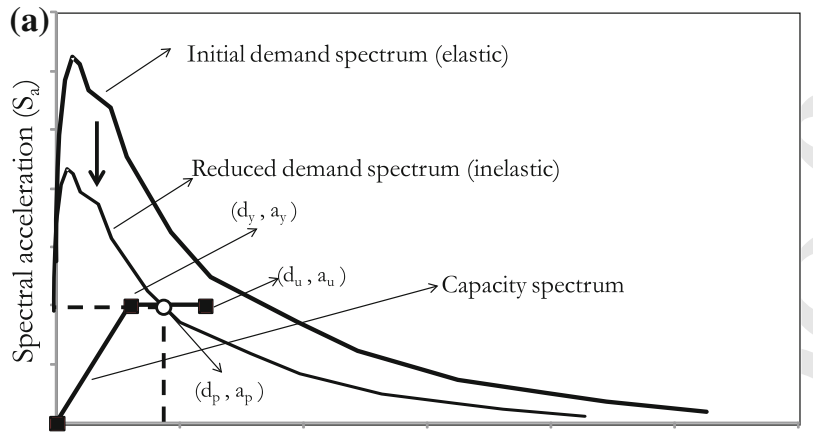

Spectral displacement $\left(\mathrm{S}_{\mathrm{d}}\right)$

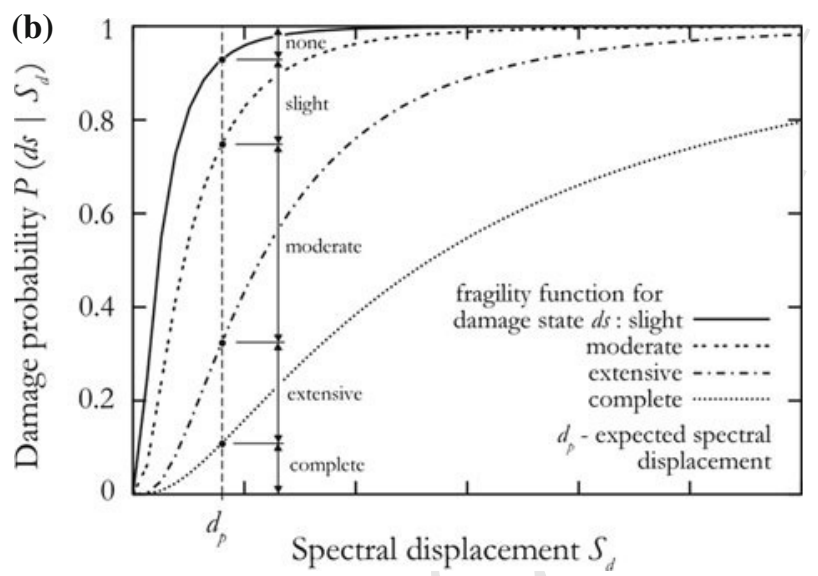

Fig. 1 a Performance point $\left(d_{p}, a_{p}\right)$ computation through the MADRS iterative procedure. b Cumulative damage probabilities given a specific $\mathrm{d}_{\mathrm{p}}$ through the fragility curve

$$
P\left[d_{s} \mid d_{p}\right]=\Phi\left[\frac{1}{\beta} \ln \left(\frac{d_{p}}{S_{d, k}}\right)\right]
$$

where $\Phi$ is the normal cumulative distribution function and $\beta$ the normalised standard deviation of the natural logarithm of the displacement threshold $S_{\mathrm{d}, \mathrm{k}}$ and $\mathrm{k}=1,2,3,4$, represent the damage state: 1-slight, 2-moderate, 3-extensive and 4-complete.

The damage limit states $S_{\mathrm{d}, \mathrm{k}}$ are directly identified on the capacity curve as a function of the yielding $\mathrm{d}_{\mathrm{y}}$ and of the ultimate $\mathrm{d}_{\mathrm{u}}$ displacements (Lagomarsino and Giovinazzi 2006):

$$
\begin{aligned}
& \mathrm{S}_{\mathrm{d}, 1}=0.7 \mathrm{~d}_{\mathrm{y}} \\
& \mathrm{S}_{\mathrm{d}, 2}=1.5 \mathrm{~d}_{\mathrm{y}} \\
& \mathrm{S}_{\mathrm{d}, 3}=0.5\left(\mathrm{~d}_{\mathrm{y}}+\mathrm{d}_{\mathrm{u}}\right) \\
& \mathrm{S}_{\mathrm{d}, 4}=\mathrm{d}_{\mathrm{u}}
\end{aligned}
$$

These damage states can be directly correlated with the EMS-98 damage states. In fact, the first three damage levels have a direct correspondence with the first three damage levels of the EMS-98 scale while the complete damage level $(\mathrm{k}=4)$ is representative of both very serious damage and of the building destruction (collapse), as these situations can hardly be distinguished within a mechanical-based model (Lagomarsino and Giovinazzi 2006). 
As already stated, the equivalent qualitative description of the damage for both masonry and reinforced concrete is assumed to be that provided by the EMS-98 (Grunthal 1998) macroseismic scales

The normalised standard deviation of the natural logarithm can be computed as a function of the ductility, $\mu$, (after Braga et al. 1982):

$$
\beta=0.4 \ln \mu(\mathrm{k}=1,2,3,4)
$$

Therefore, the theoretical damage probability will be given by the combination of spectral demand that will be modified due to site and topographic effects and the shape and control points of the damage functions $\left(d_{y}, a_{y}, d_{u}, a_{u}, \mu\right)$.

The iterative process of damage function calibration will be done using the observed data, removing those in which topographic effects cannot be neglected when compared with soil effects ( $\mathrm{V}_{\mathrm{S}}^{30}$ amplification). Then a two-stage process will be followed: (a) The first stage will select the ground motion prediction equation (GMPE) and the $\mathrm{V}_{\mathrm{S}}^{30}$ model that better approaches to the observed damage, assuming initial damage functions; (b) Using the selected GMPE and $\mathrm{V}_{\mathrm{S}}^{30}$ model, the damage functions will be obtained through an iterative process starting from the initial curves until a minimum difference between theoretical and observed (residuals) is obtained.

A more detailed explanation of this process will be given with an example in next paragraph.

\section{Vulnerability calibration of the Haitian model building types}

\subsection{Building stock database. Identification of model building types}

With the aim of simplifying the seismic risk assessment, the building exposure stock in the city, under study has to be classified into model building types (MBT), each which one representing a group of buildings with similar structural architectural features. The classification has to be detailed, to guarantee realistic outcomes, as well as generic, to allow the classification of buildings in categories.

To this end, in July 2011 the SISMO-HAITI working group carried out a field campaign in Port-au-Prince, guided by local civil engineers, in order to examine the exposure and the local construction techniques. Additionally, the Ministry of Public Works of Haiti (MTPTCMinistère des Travaux Publics, Transports et Communications) provided a building database compiled after the 2010 earthquake, containing structural information, damage state and use of 86,822 buildings in Port-au-Prince.

Based on both sources of information, the exposure was classified into eight MBT according to the materials of their structure and walls, and the number of stories. Buildings placed in steep slopes were excluded as well as those located on the Fort National hill, since their performance could have been affected by topographic effects. The reason is because the GMPE used in this study do not consider the topographic amplification, hence the damage predicted by the models for those buildings would not be comparable to the observed damage, and consequently, they cannot be used to calibrate the vulnerability model.

After removing the buildings located in steep slopes and on the Fort National, 67,490 were left in the database to be used in the study. Table 1 shows a summary of the MBT classification and the distribution percentage is represented in Fig. 2.

Three MBT with reinforced concrete structure have been identified (RC-SW, RC-CB, RC$\mathrm{UM})$, which are the most resistant ones according to the percentage of observed complete 
Table 1 Classification of the building stock in Port-au-Prince into different model building types

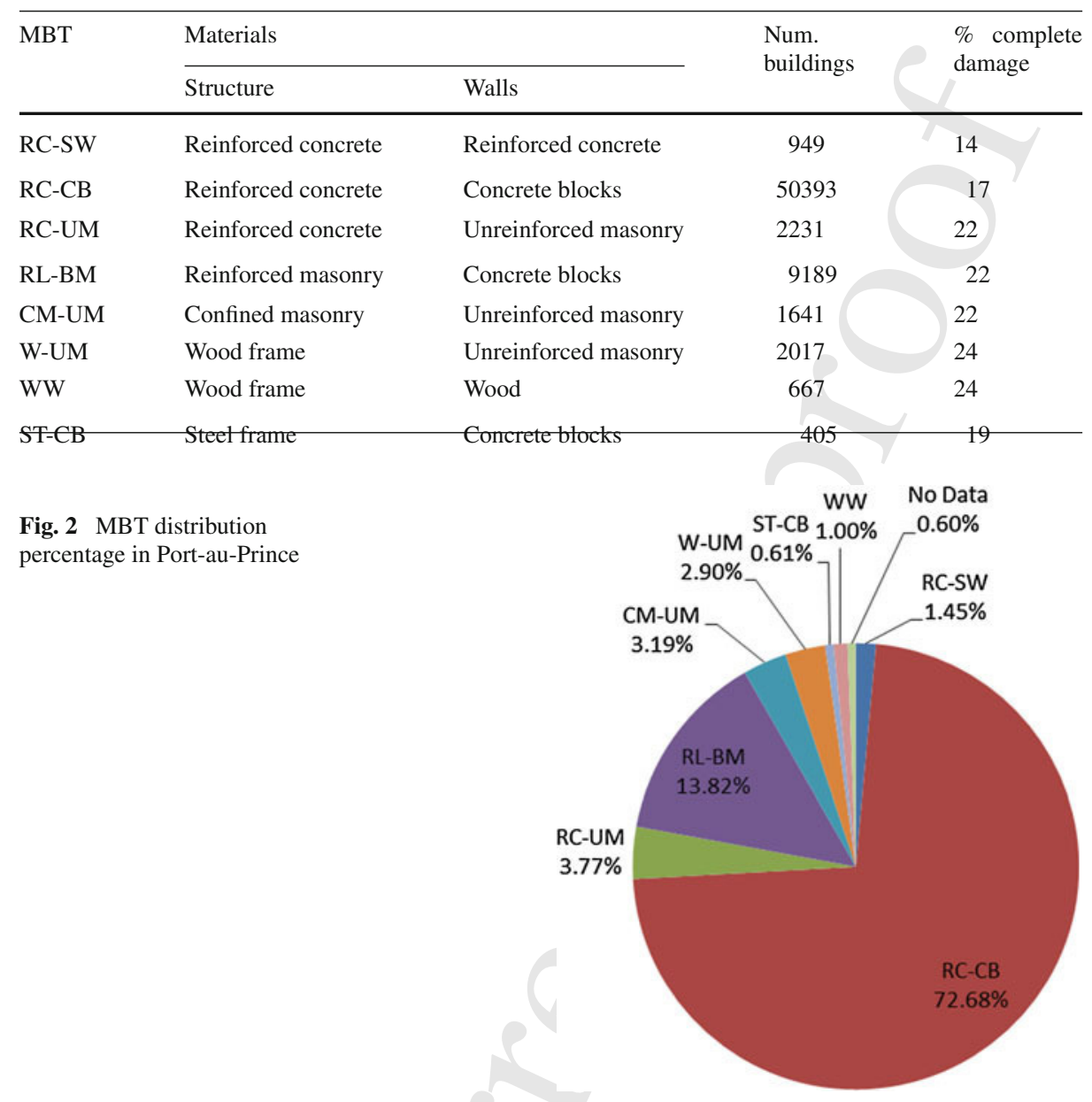

damage they suffered in the 2010 earthquake (Table 1). RC-CB is the predominant MBT in the city, since it represents almost the $73 \%$ of the buildings (Fig. 2). Two MBT represent buildings with masonry structure (RL-BM, CM-UM); two MBT are representative of wood frame houses (W-UM, WW); while buildings with steel structure have been grouped in one MBT (ST-CB).

WW and ST-CB typologies have been excluded of the study due to the small sample size (as Fig. 2 illustrates, they represent only 1 and $0.61 \%$ of the buildings in the urban area of Port-au-Prince, respectively). Therefore, the final number of buildings used in the calibration is 66,420 .

A detailed description of the buildings, materials, construction techniques and seismic behaviour can be found in DesRoches et al. (2011), Lang and Marshall (2011) and Marshall et al. (2011), amongs others. Next, we will summarize a brief description according to the main typologies used in this research.

RC-CB describes reinforced concrete frame buildings with concrete block infill. These buildings showed, at the time of the earthquake, a high vulnerability due to wrong con- 
struction techniques. For example, they have very thin columns and often reinforced with deformed and sometimes smoothed bars which are not adequate. Column and joint transverse reinforcement was minimal and not correctly spaced. Concrete and mortar quality appeared to vary significantly.

RC-SW describes reinforced concrete frame buildings with reinforced concrete wall. Although it's only a small fraction of the building inventory, they also showed the same structural problems in the reinforcement and the quality of the materials explained for RC$\mathrm{CB}$.

RC-UM describes reinforced concrete frame building with unreinforced masonry infills. As with numerous other structures observed, the columns and joints had little transverse reinforcement. No mechanical connection is made between the masonry wall panel and the columns, floor, or roof slabs.

RL-BM describes reinforced masonry with concrete blocks infill. In reinforced masonry, rebar is inserted into horizontal mortar beds and into the vertical "cells" or openings in the concrete block and then these cells with rebar are filled with mortar.

CM-UM describes confined masonry with unreinforced masonry infills. In Haiti, this building typology results in a gap between the top of the wall and the beam or slab above, prohibiting vertical load transfer. Therefore, two-way bending cannot develop across the wall. For this reason, true confined masonry construction is not observed in Haiti and is usually referred as "wall-first" construction.

W-UM describes braced timber framing with unreinforced masonry infill. They are also named as Colombage. Foundations, retaining walls and perimeter walls are typically constructed of stone masonry.

The six MBT considered in the study have been sub-categorized depending on their number of stories into low-rise (1-3 stories) and mid-rise (4-6 stories). In Port-au-Prince, $99.3 \%$ of the buildings are low-rise.

Regarding the use, $89 \%$ are residential buildings (66\% are single family dwellings and $23 \%$ are apartments) and the rest are destined to other uses (education, industry, commerce, government, religion, health, others), according to the database.

\section{$4.2 \mathrm{~V}_{\mathrm{S}}^{30}$ velocity structure of Port-au-Prince}

The shallow structure at one site located on the sedimentary Holocene alluvial fan deposits in Port-au-Prince town has been studied using the Spatial Autocorrelation method (SPAC). This measurement represents an independent test of the $\mathrm{V}_{\mathrm{S}}^{30}$ values obtained with other methods (Cox et al. 2011). The measurement was carried out at National Palace open space and an $S$-wave velocity profile has been obtained by means of inversion from the Rayleigh wave dispersion curve.

Vertical components of soil motion, excited by ambient vibration, were recorded using circular-shaped arrays by means of five VSE-15D sensors surrounding a sixth central sensor with same characteristics. We used three different radii: 5, 10 and $20 \mathrm{~m}$, respectively, considering the available space dimension. All records have been analysed by using an implementation of the SPAC method (Aki 1957). In order to obtain the correlation coefficient $\rho(f, R)$, the cross correlations between records on the circle and the central station were calculated in frequency domain (Fig. 3a). Then, the azimuthal average was divided by the autocorrelation at the central station. Finally, phase-velocity of the Rg-wave c(f) was computed for each frequency f (Fig. 3b), and applying a previous polynomical fit of the $\rho$ versus $f$ relation for smoothing. The frequencies of the obtained dispersion curve ranged from 4.0 to $12.9 \mathrm{~Hz}$ and the phase velocity values varied between 275 and $417 \mathrm{~m} / \mathrm{s}$ 

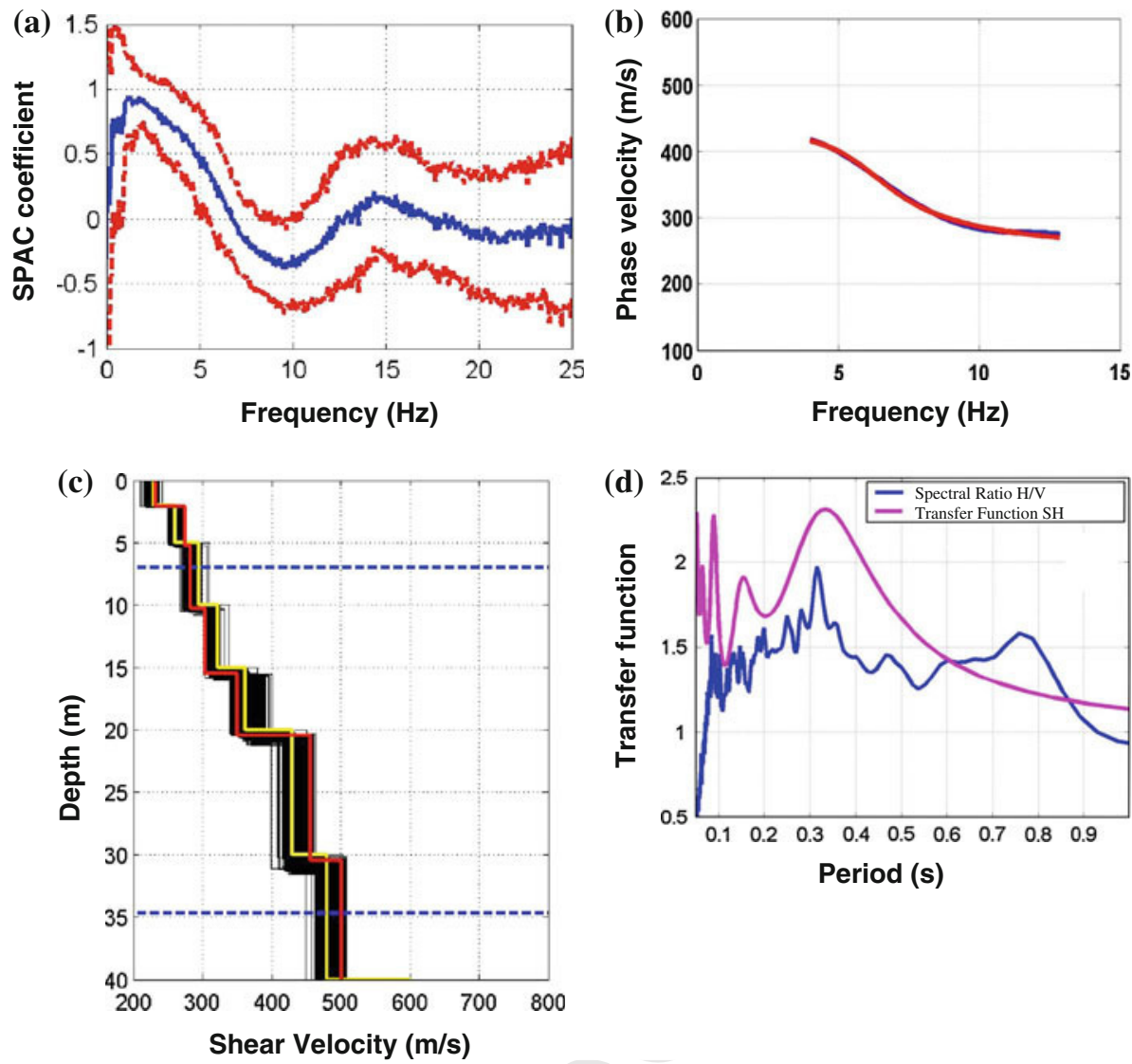

Fig. 3 Some results obtained at National Palace: a SPAC coefficient for a radius of $20 \mathrm{~m}$. b Smoothed fundamental-mode Rg dispersion curve (blue colour) and theoretical dispersion curve (red color) obtained from Shear-wave velocity model. c Shear-wave velocity model (red colour) derived from inversion of phase velocities, initial model represented by yellow colour. $\mathbf{d} \mathrm{H} / \mathrm{V}$ spectral ratio (blue colour) and theoretical 1Dtransfer function (pink colour)

A ground structure consisting of plane-horizontal homogeneous layers overlying a halfspace, defined in terms of shear-wave velocities, was obtained by inversion of Rg-wave phase velocity dispersion curves for sample site. Such an iterative inversion method requires building up a suitable initial ground model, the $\lambda / 3$ criterion (Tokimatsu 1997) from the dispersion data was applied. The initial model was made up of seven homogeneous layers of different thick, overlaying a half-space of $600 \mathrm{~m} / \mathrm{sec}$.

The result shows a shear-wave velocity structure (Fig. 3c) with shear-wave velocity values ranging between 233 and $501 \mathrm{~m} / \mathrm{s}$. Although the good agreement found between experimental and theoretical dispersion curves (Fig. 3b) does not ensure the uniqueness of the resulting model (but only its compatibility with the phase velocity data), the uncertainty in averaged velocities is often significantly smaller. In particular, the average shear-wave velocity of the upper $30 \mathrm{~m}\left(\mathrm{~V}_{\mathrm{S}}^{30}\right)$ can be computed. The value found for $\mathrm{V}_{\mathrm{S}}^{30}$ is $331 \mathrm{~m} / \mathrm{s}$. Attending to the $\mathrm{V}_{\mathrm{S}}^{30}$ value, the Holocene alluvial fan deposits can be classified in this place as into class 
$\mathrm{D}$, according to NEHRP (2003) soil classification. This result is agreement with $\mathrm{V}_{\mathrm{S}}^{30}$ values obtained with MASW method (Cox et al. 2011).

The HVSR method (Nakamura 1989) was used to determine the predominant period of soil at the National Palace area (Fig. 3d). Ambient vibration measurements were recorded using a single three-component seismograph. The signal processing was carried out following García-Jerez et al. (2006), including the use of time-dependent plots (Almendros et al. 2004) for stability control. The records were first divided into non-overlapping $20 \mathrm{~s}$ time windows. In order to reduce the finite-window effects, the windows were tapered over $10 \%$ of its length by using a Hanning taper before taking Fourier transform. The records were transformed to the frequency domain by using the Discrete Fourier Transform algorithm (DFT). A single horizontal spectrum was generated by addition of the NS and EW horizontal power spectra, and HVSR was separately computed for all time intervals and plotted in a time-dependent diagram (ratiogram). Finally, the horizontal-to-vertical ratios were averaged over the good quality time intervals. The characteristic predominant period at the National Palace area, obtained from $\mathrm{H} / \mathrm{V}$ spectral ratio, has been compared with the predominant period calculated from the one-dimensional transfer functions for vertically incident $S$ wave. The fundamental resonance frequency of the inverted model for vertically incident $S$ waves matches well the experimental value of $0.33 \mathrm{~s}$. (Fig. 3d). This result is in agreement with the predominant of soil calculated from $\mathrm{H} / \mathrm{V}$ spectral ratio.

Figure 4 shows the comparison among the $V_{S}^{30}$ values proposed by Cox et al. (2011) and the values obtained in this work. As we can see there is a good agreement between both values. Therefore, as $\mathrm{V}_{\mathrm{S}}^{30}$ is needed in order to obtain the ground motion in the city for the seismic risk estimation and we will assume the $\mathrm{V}_{\mathrm{S}}^{30}$ values proposed by Cox et al. (2011),

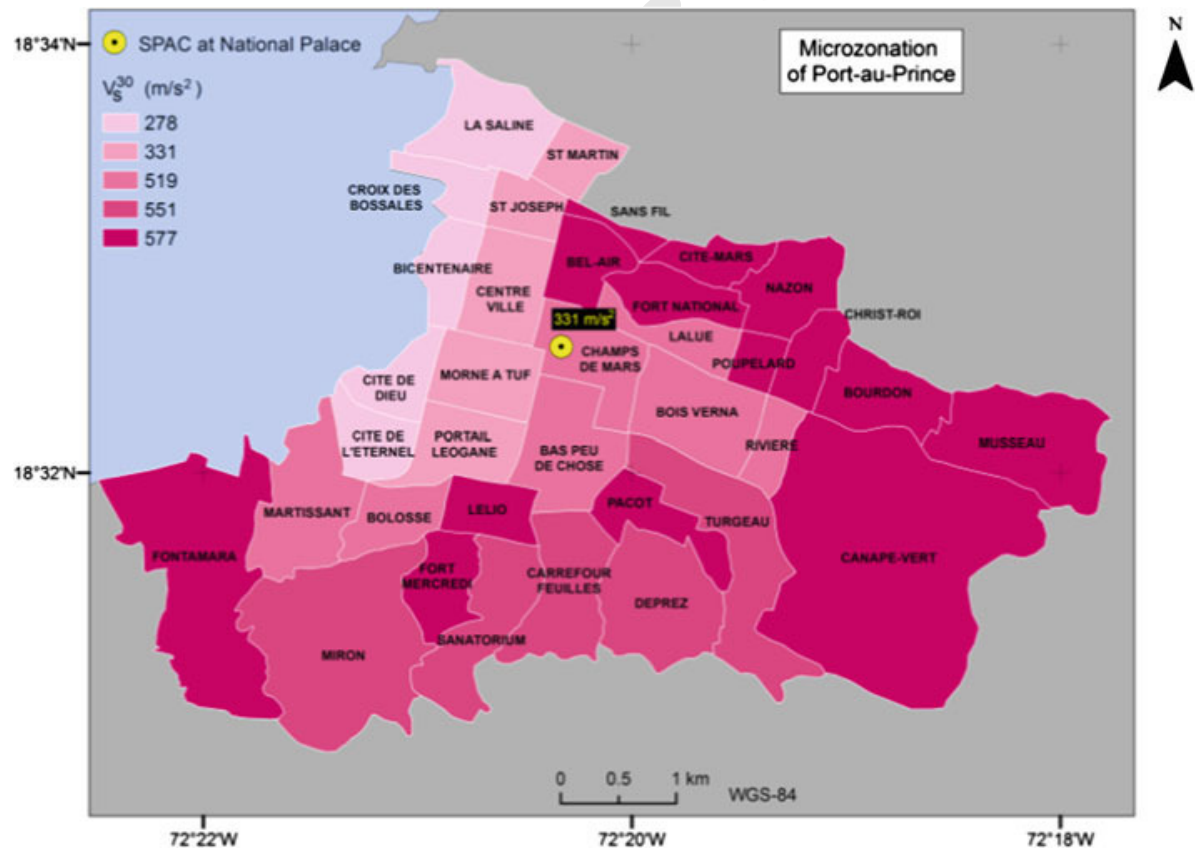

Fig. $4 \mathrm{~V}_{\mathrm{S}}^{30}$ proposed by Cox et al. (2011) and assigned to the different districts in the city. As a yellow dot, the SPAC measurement obtained in this paper has been represented 

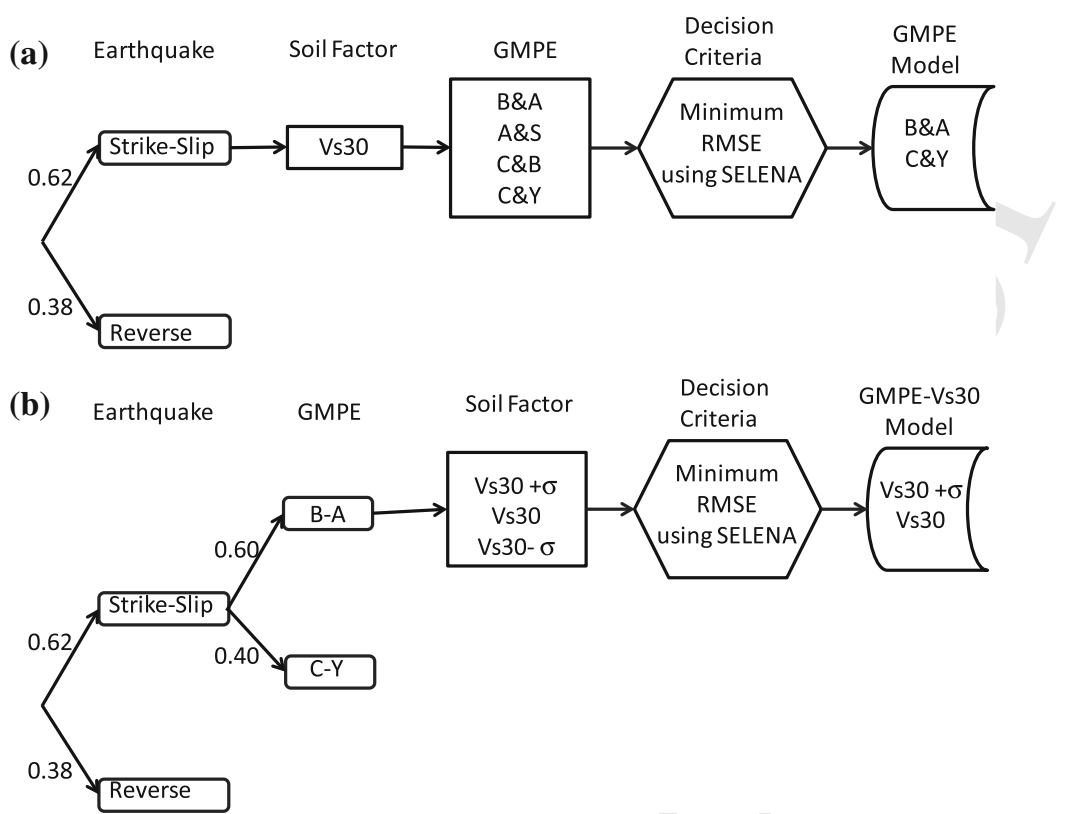

Fig. 5 Computation scheme for: a selection of the GMPE Model and $\mathbf{b}$ the GMPE-Vs30 Model

as shown in Fig. 4, and in the future we will carry out a detailed microzonation in order to obtain $\mathrm{V}_{\mathrm{S}}^{30}$ for all the districts in the city.

\subsection{First-stage: GMPE and $\mathrm{V}_{\mathrm{S}}^{30}$ calibration}

Currently there is still not enough ground motion data to estimate specific GMPEs for Haiti. Therefore, as a starting point, we will investigate the application of the NGA models (Abrahamson and Silva 2008-A\&S; Boore and Atkinson 2008 —B\&A; Campbell and Bozorgnia 2008 - C\&B; and Chiou and Youngs 2008 - C\&Y) by a comparison of the theoretical damage results with the observed. These models take into consideration the soil amplifications using Vs30 as a parameter.

Therefore, in order to select a GMPE- $\mathrm{V}_{\mathrm{S}}^{30}$ model that can be used to compute the damage in Haiti, we will follow the next steps:

(a) SELENA will be used to compute theoretical damage probabilities by using a logic tree with two branches for the source parameters of the 2010 earthquake and one $\mathrm{V}_{\mathrm{S}}^{30}$ model (Fig. 5a). A computation will be done for each NGA GMPE. Two GMPE equations will be selected as those that provide the minimum root mean square error (RMSE). Figure 6 $a, b$, shows the obtained RMS for the main typologies where it can be seen that B\&A and C\&Y GMPE provide the lowest RMSE.

(b) Next, SELENA will be used to compute theoretical damage probabilities by using a logic tree with two branches for the source parameters of the 2010 earthquake and computing damage probabilities for $\mathrm{V}_{\mathrm{S}}^{30} ; \mathrm{V}_{\mathrm{S}}^{30}+$ sigma and $\mathrm{V}_{\mathrm{S}}^{30}$ - sigma, using only the GMPEs selected in step a) (Fig. 5b). Two $\mathrm{V}_{\mathrm{S}}^{30}$ models will be selected as those that provide the minimum RMSE. Figure $6 c$, d shows the obtained RMSE for the main typology (RC-CB) 


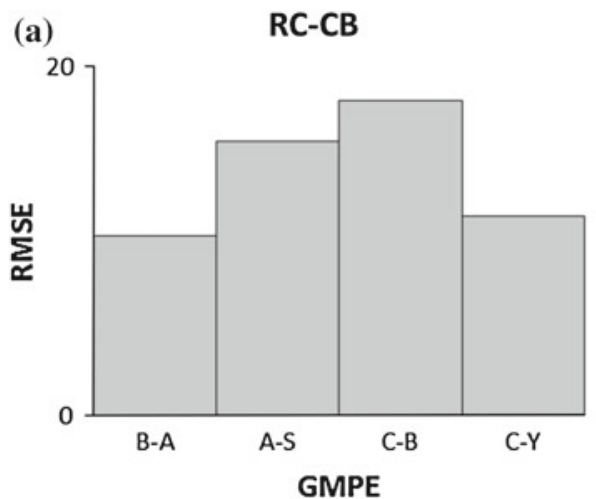

(c)

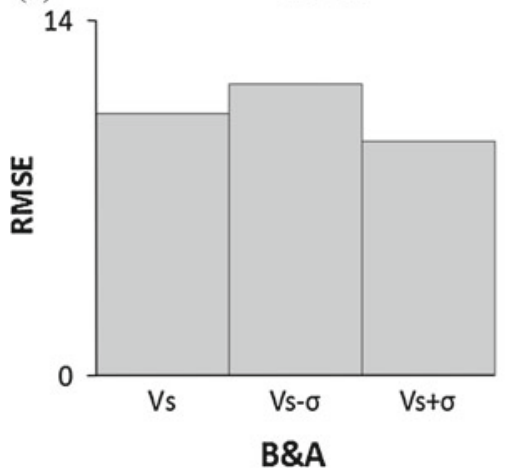

(b)

RL-BM

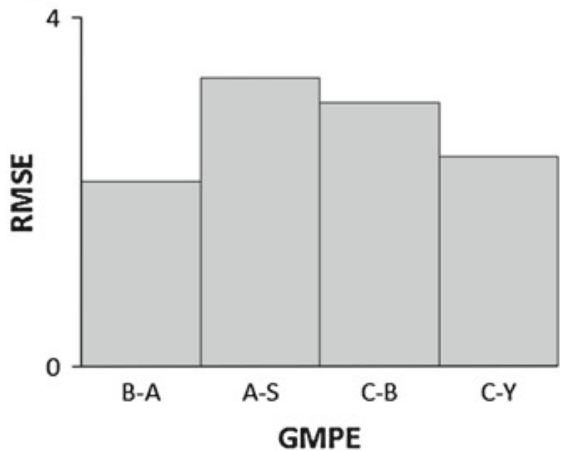

(d)

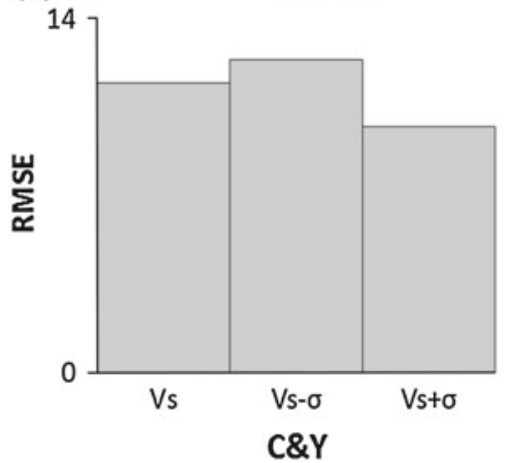

Fig. 6 Comparison between the RMSE of the residuals obtained with the four GMPE, for the two prevalent MBT: a RC-CB and b RL-BM. Comparison between the RMSE of the residuals obtained using three different values of $\mathrm{Vs}^{30}$ (mean, mean- $\sigma$, mean $+\sigma$ ) with the two selected GMPE: c B\&A and d C\&Y; for the prevalent MBT (RC-CB)

and both GMPE (B\&A and C\&Y) where it can be seen that in both cases the minimum RMSE are obtained for $\mathrm{V}_{\mathrm{S}}^{30}$ and $\mathrm{V}_{\mathrm{S}}^{30}+$ sigma.

In these steps, the model building types had to be assigned an initial damage function. Currently, only Hancilar et al. (2013) has developed specific fragility functions for Haiti. The authors provide empirical fragility functions derived from remote sensing and also based on field data. In both cases the obtained results can be used for rapid damage/loss assessments in future events but the authors indicate that they need further improvements to be applied in a detailed seismic risk study. Besides, they can not be used in an analytical procedure as the one used in our research.

On the other hand, several authors have been providing analytical damage functions (capacity curve and fragility functions) for model building types in different regions of the world. First, we can mention the functions provided by HAZUS (FEMA,2008). They provide damage function for fifteen model building types, three classes of height, four seismic design level (High-Code; Moderate-Code; Low-Code and Pre-Code) and three seismic performance level (Superior, Ordinary and Inferior) depending on the strength and ductility. These damage functions are representative of the general exposure (i.e. represents a population of a given 
Table 2 Initial capacity curves

\begin{tabular}{lllllll}
\hline MBT & Comparable with & Author & & \multicolumn{3}{l}{ Capacity curves parameters } \\
\cline { 5 - 7 } & & & Dy $(\mathrm{m})$ & Ay $\left(\mathrm{m} / \mathrm{s}^{2}\right)$ & Du $(\mathrm{m})$ & $\mu$ \\
\hline RC-SW & RC2-I & L\&G & 0.0320 & 6.60213 & 0.0960 & 3 \\
RC-CB & RC1-I & L\&G & 0.0239 & 4.92462 & 0.0716 & 3 \\
RC-UM & C3-Pre code & HAZUS & 0.0030 & 0.98100 & 0.0343 & 5 \\
RL-BM & M7-Pre code & L\&G & 0.0030 & 4.98000 & 0.0233 & 7.85 \\
CM-UM & M6-Medium code & L\&G & 0.0040 & 3.51198 & 0.0236 & 5.98 \\
W-UM & M6-Pre code & L\&G & 0.0036 & 3.17844 & 0.0171 & 4.79 \\
\hline L\&G: La & & & & & &
\end{tabular}

L\&G: Lagomarsino and Giovinazzi (2006), HAZUS: FEMA (2008)

Table 3 Initial fragility functions (damage limit states $S d, i$ and normalised standard deviation $\beta$ ) for slight (i $=1)$, moderate $(i=2)$, extensive $(i=3)$ and complete $(i=4)$ damage states

\begin{tabular}{lllllllll}
\hline MBT & $\mathrm{S}_{\mathrm{d}, 1}$ & $\beta$ & $\mathrm{S}_{\mathrm{d}, 2}$ & $\beta$ & $\mathrm{S}_{\mathrm{d}, 3}$ & $\beta$ & $\mathrm{S}_{\mathrm{d}, 4}$ & $\beta$ \\
\hline RC-SW & 0.0224 & 0.33 & 0.0320 & 0.40 & 0.0480 & 0.54 & 0.0960 & 0.70 \\
RC-CB & 0.0167 & 0.33 & 0.0239 & 0.40 & 0.0358 & 0.54 & 0.0716 & 0.70 \\
RC-UM & 0.0109 & 1.19 & 0.0218 & 1.15 & 0.0549 & 1.15 & 0.1280 & 0.92 \\
RL-BM & 0.0021 & 0.39 & 0.0030 & 0.57 & 0.0081 & 0.92 & 0.0233 & 1.18 \\
CM-UM & 0.0028 & 0.38 & 0.0040 & 0.52 & 0.0089 & 0.82 & 0.0236 & 1.04 \\
W-UM & 0.0025 & 0.36 & 0.0036 & 0.48 & 0.0070 & 0.73 & 0.0171 & 0.93 \\
\hline
\end{tabular}




\subsection{Second-stage: damage function calibration}

Once GMPE and $\mathrm{V}_{\mathrm{S}}^{30}$ model have been chosen (two GMPE equations and two $\mathrm{V}_{\mathrm{S}}^{30}$ models), SELENA will compute theoretical damage probabilities using the logic tree showed in Fig. 7 for each model building type. As Port-au-Prince urban area has a size and a soil variability that can lead to important differences in the ground motion values for each district, the geounits has been classified into three subgroups (Fig. 8) that will be used to compare observed and theoretical damage probabilities. The weighted (according to the total number of building in each subgroup) error (abs (theoretical-observed)) will be computed for each subgroup and also the weighted error for all the subgroups. The damage functions parameters (yield and ultimate displacement and acceleration, and ductility) will be iteratively modified until a minimum error is obtained. A summarized example for the RC-CB typology can be observed in Fig. 9.

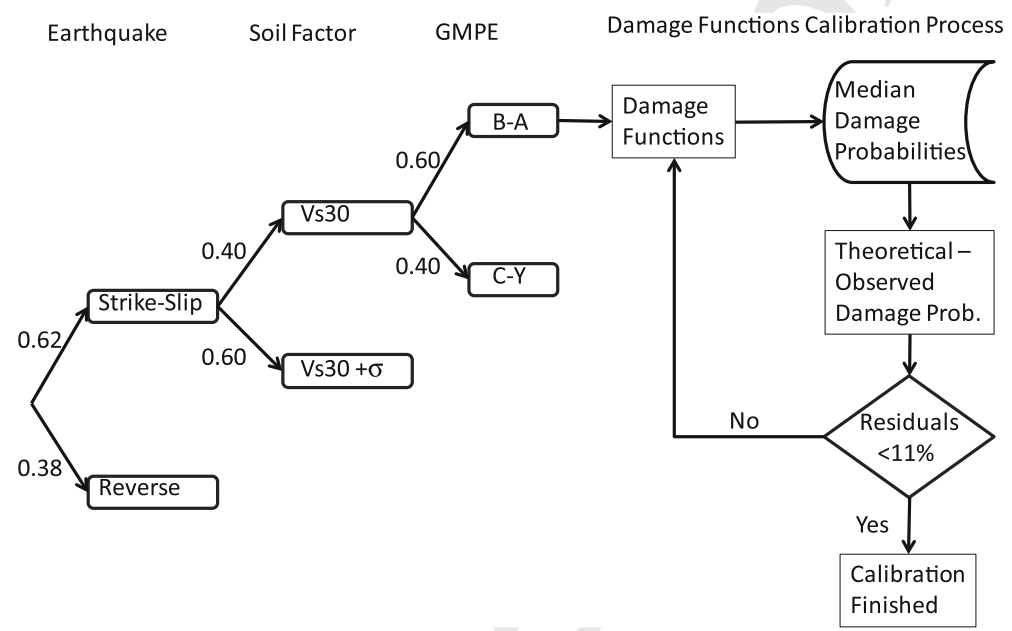

Fig. 7 Computations scheme of the damage function calibration process. Epistemic uncertainty in earthquake source and site-specific ground motion has been represented using a logic tree

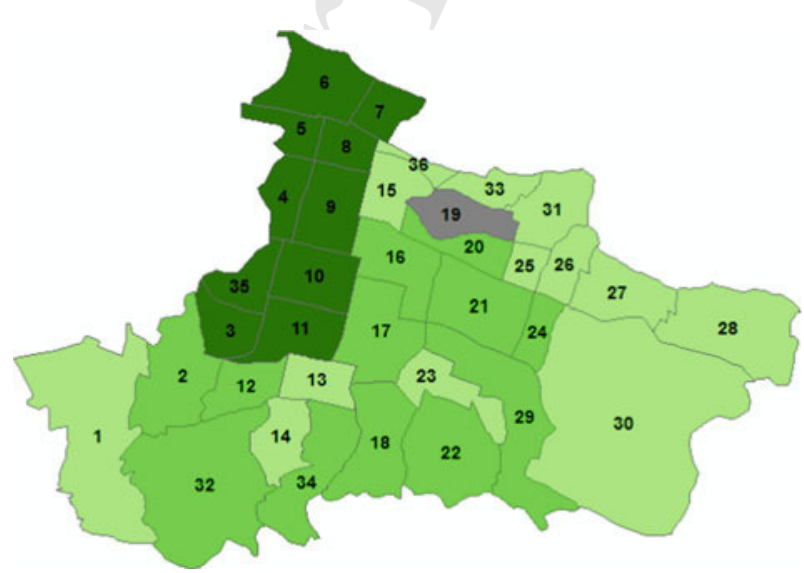

Fig. 8 Map of the geounits classified into 3 sub-groups. Geounit 19 was removed to avoid using damage data with a big influence of topographic effects

\section{Springer}




\begin{tabular}{|c|c|c|c|}
\hline & \multicolumn{3}{|c|}{ Capacity Curves Parameters } \\
\hline & $\mathrm{Sd}(\mathrm{m})$ & $\mathrm{Sa}\left(\mathrm{m} / \mathrm{s}^{2}\right)$ & $\mu$ \\
\hline \multirow{3}{*}{ Initial } & 0.0000 & 0.0000 & \multirow{3}{*}{3} \\
\hline & 0.0239 & 4.9246 & \\
\hline & 0.0716 & 4.9246 & \\
\hline \multirow{3}{*}{$\begin{array}{c}2^{\text {nd }} \\
\text { Iteration }\end{array}$} & 0.0000 & 0.0000 & \multirow{3}{*}{3} \\
\hline & 0.0400 & 4.9246 & \\
\hline & 0.0716 & 4.9246 & \\
\hline \multirow{3}{*}{ Final } & 0.0000 & 0.0000 & \multirow{3}{*}{2} \\
\hline & 0.0500 & 5.7000 & \\
\hline & 0.0750 & 5.7000 & \\
\hline
\end{tabular}

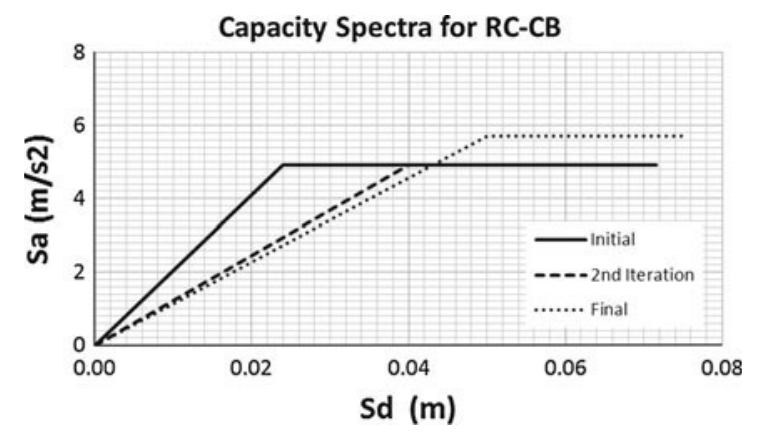

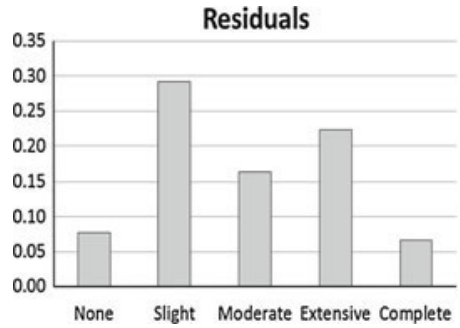

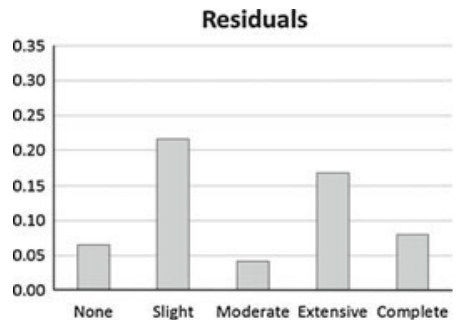

Residuals

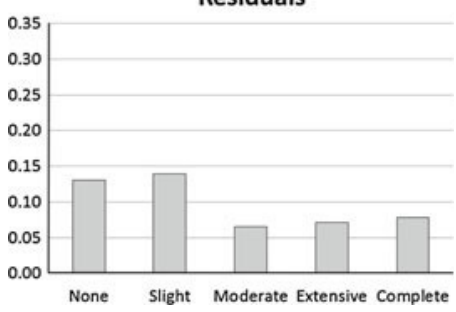

Fig. 9 Iterative procedure for obtaining the final capacity curve parameters. After using the proposed capacity curve parameters, damage probabilities were computed and compared with observed probabilities. The iterations stop when obtaining minimum residuals. Note for demonstrative purposes only three iterations have been shown (Initial, 2nd iteration and final iteration)

On the other hand, Fig. 10 shows the comparison between the initial error and the final error and Tables 4 and 5 summarized the calibrated damage function parameters.

One source of uncertainty when the goal of the study is the calibration of damage functions comes from the fact that, often, the observed damage assigned in the database is established by visual inspection of the buildings and sometimes the difference from none to slight or 

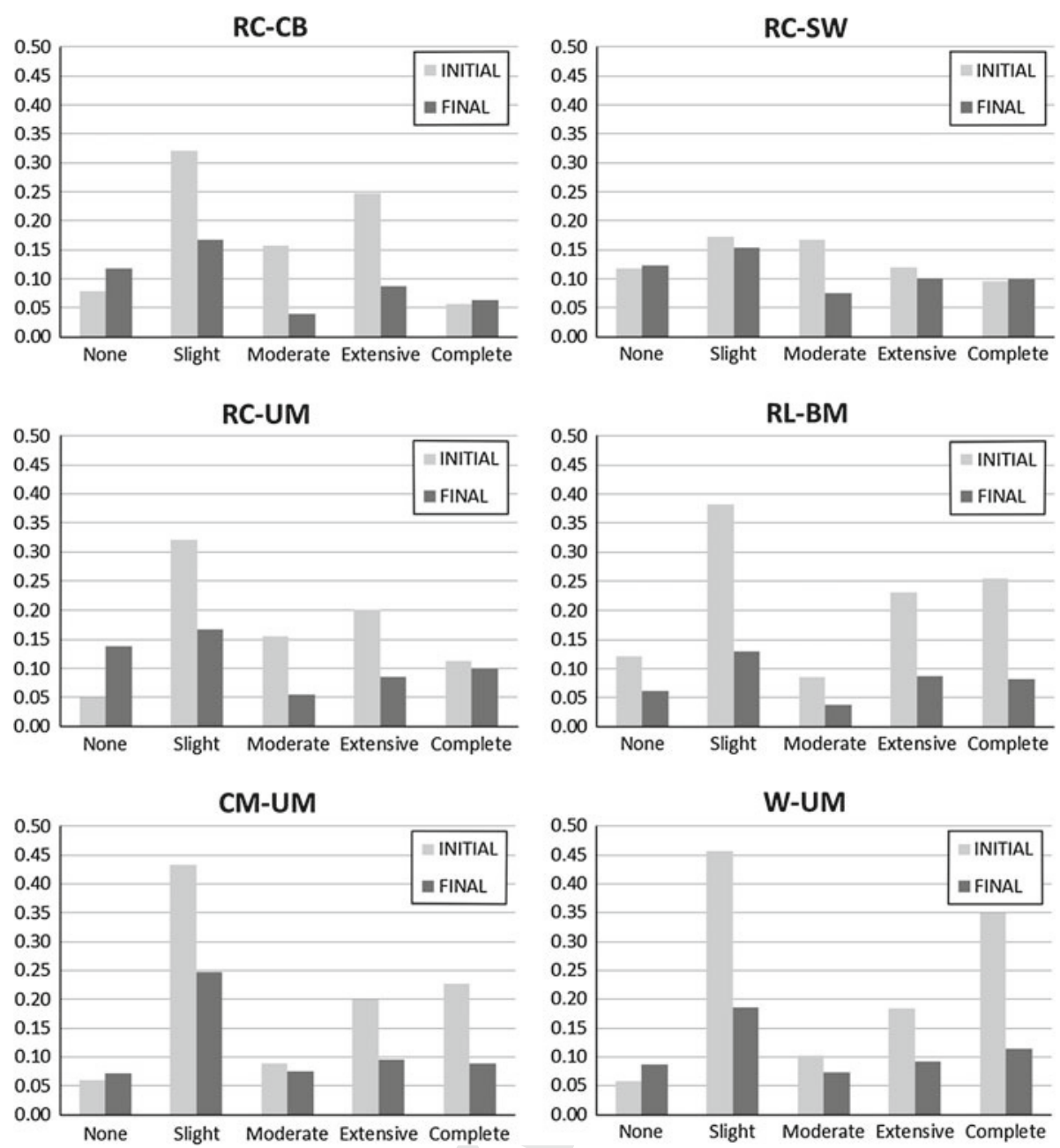

Fig. 10 Comparison of initial and final residuals for each one of the model building types

Table 4 Final capacity curves (parameters after iterations)

\begin{tabular}{lllll}
\hline MBT & Dy $(\mathrm{m})$ & Ay $\left(\mathrm{m} / \mathrm{s}^{2}\right)$ & Du $(\mathrm{m})$ & $\mu$ \\
\hline RC-SW & 0.0450 & 6.2021 & 0.0900 & 2 \\
RC-CB & 0.0500 & 5.7000 & 0.0750 & 2 \\
RC-UM & 0.0350 & 5.6000 & 0.0550 & 2 \\
RL-BM & 0.0400 & 5.4000 & 0.0600 & 2 \\
CM-UM & 0.0600 & 3.8000 & 0.1200 & 2 \\
W-UM & 0.0520 & 3.8500 & 0.0900 & 3 \\
\hline
\end{tabular}

from moderate to extensive is not so well done. Then it can happen that some of the slight damage is included into none or vice versa and the same happens between moderate and extensive damage. Therefore, a comparison has been made between the observed damaged

\section{Springer}


Table 5 Final fragility functions (damage limit states $S d, i$ and normalised standard deviation $\beta$ ) for slight (i $=1)$, moderate $(i=2)$, extensive $(i=3)$ and complete $(i=4)$ damage states

\begin{tabular}{lllllllll}
\hline MBT & $\mathrm{S}_{\mathrm{d}, 1}$ & $\beta$ & $\mathrm{S}_{\mathrm{d}, 2}$ & $\beta$ & $\mathrm{S}_{\mathrm{d}, 3}$ & $\beta$ & $\mathrm{S}_{\mathrm{d}, 4}$ & $\beta$ \\
\hline RC-SW & 0.0315 & 0.30 & 0.045 & 0.32 & 0.0563 & 0.38 & 0.090 & 0.50 \\
RC-CB & 0.0350 & 0.30 & 0.050 & 0.32 & 0.0563 & 0.38 & 0.075 & 0.50 \\
RC-UM & 0.0245 & 0.30 & 0.035 & 0.32 & 0.0400 & 0.38 & 0.055 & 0.50 \\
RL-BM & 0.0280 & 0.30 & 0.040 & 0.32 & 0.0450 & 0.38 & 0.060 & 0.50 \\
CM-UM & 0.0420 & 0.33 & 0.060 & 0.40 & 0.0750 & 0.54 & 0.120 & 0.70 \\
W-UM & 0.0364 & 0.33 & 0.052 & 0.40 & 0.0615 & 0.54 & 0.090 & 0.70 \\
\hline
\end{tabular}

(a)

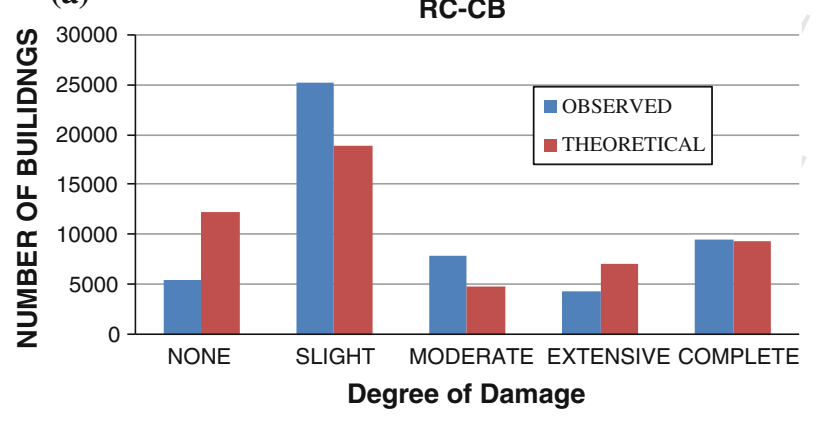

(b)

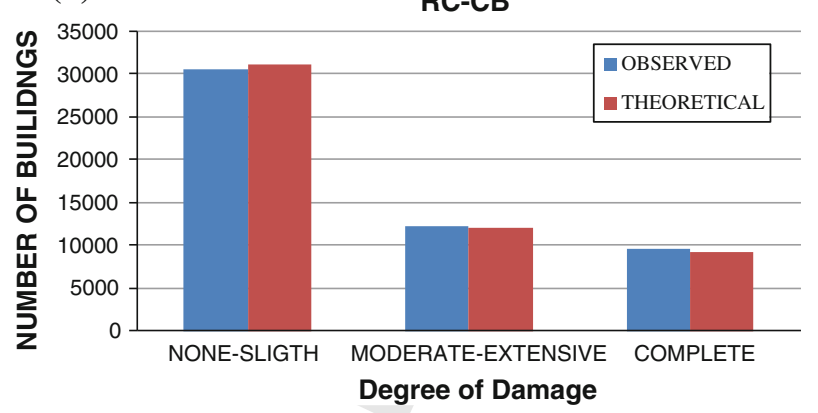

Fig. 11 Comparison between observed and theoretical damaged buildings in Port-au-Prince: a Using five damage states. b Using three damage states

buildings in Port-au-Prince and the theoretical damage using damage functions from Tables 4 and 5. Figure 11 shows the comparison when using the five damage states and when grouping damage states in three types. As can be seen the differences between theoretical and observed is minimum when damage is grouped in three types what also indicates that in observed damage database often damage states none and slight cannot be well distinguish as well as damage states moderate and extensive.

In any case theoretical damage is always lower than observed due to the fact that in many cases there are additional factors which influence the damage. Those factors cannot be represented with the proposed damage functions (for example, non-structural damage, building geometry, etc.) or the site-specific ground motion model (for example, topographic effects, landslides, etc). 
Finally, the obtained results will be used for future seismic risk scenarios of probable earthquakes in the country and they will be refined as specific parameters for the country is are obtained (for example, detailed microzonation or specific GMPEs)

\section{Conclusions}

A detailed database of the observed damage after the 2010 Haiti earthquake has been compiled and analysed in this paper with the goal of developing calibrated damage functions for the main model building types in the country. From the obtained results the following conclusions can be draft:

1. The important observed damage in the National Palace are in agreement with the $\mathrm{V}_{\mathrm{S}}^{30}$ values obtained in this study: An average velocity of $331 \mathrm{~m} / \mathrm{s}$, which is in agreement with previous works in the city (Cox et al. 2011) and that can be classified into class $\mathrm{C}$ according to Eurocode 8 (class D according to NEHRP). Although a more detailed microzonation should be done in the city, as a first step, the $\mathrm{V}_{\mathrm{S}}^{30}$ model proposed by Cox et al. (2011) can be used for seismic hazard and risk computation in the city.

2. In the calibration process, we have observed that, in order to obtain seismic risk scenarios in the city, the NGA attenuation models proposed by Boore and Atkinson (2008) or Chiou and Youngs (2008) in combination with the $\mathrm{V}_{\mathrm{S}}^{30}$ or $\mathrm{V}_{\mathrm{S}}^{30}$ plus sigma proposed by Cox et al. (2011) are the most appropriate because brings the lowest residuals.

3. Additionally, a set of specific damage functions for the main Haitian model building types have been obtained through an iterative calibration process using the damage from the 2010 Haiti earthquake. The theoretical damage obtained with these functions shows a better agreement with the observed damage in the moderate, extensive and complete states.

4. Finally, when grouping the observed damage in only three damage states: none-slight, moderate-extensive, and complete, we observe the best agreement between theoretical and observed data, which demonstrate that, when compiling observed damage database, often damage states none and slight can not be well distinguish as well as moderate and extensive damage.

Acknowledgments This work has been developed thanks to the financial support of the Universidad Politecnica de Madrid (UPM), project SISMO-HAITI. Additionally we want to acknowledge the support of the ONEV, the CNIGS (specially Boby Piard), the MTPTC (specially Charles Baguidy), and all the Haitian people and organization which have contributed to the data compilation. We also want to thank to Dr. D. Lang and Dr. E. Erduran for their valuable contributions and the comments of two anonymous reviewers that helped to improve this paper.

\section{References}

Abrahamson N, Silva W (2008) Summary of the Abrahamson \& Silva NGA ground-motion relations. Earthq Spectra 24(1):67-97

Almendros J, Luzon F, Posadas A (2004) Microtremors analysis at Teide Volcano (Canary Islands, Spain): assessment of natural frequencies of vibration using time-dependent horizontal-to-vertical spectral ratios. Pure Appl Geophys 161:1579-1596

Aki K (1957) Space and time spectra of stationary stochastic waves, with special reference to microtremors. Bull Earthq Res Inst 35:415-456

Applied Technology Council (ATC) (1996) Seismic evaluation and retrofit of concrete buildings. Report ATC-40, Redwood City, CA, USA, 346 p 
Applied Technology Council (ATC) (2005) Improvement of Nonlinear Static Seismic Analysis Procedures, FEMA-440. CA, USA

Boore DM, Atkinson GM (2008) Ground-motion prediction equations for the average horizontal component of PGA, PGV, and 5\%-damped PSA at spectral periods between 0.01 s and 10.0 s. Earthq Spectra 24(1):99-138

Calais E, Freed A, Mattioli G, Amelung F, Jónsson S, Jansma P, Hong SH, Dixon T, Prépetit C, Momplaisir R (2010) Transpressional rupture of an unmapped fault during the 2010 Haiti earthquake. Nat Geosci 3:794-799

Campbell KW, Bozorgnia Y (2008) NGA ground motion model for the geometric mean horizontal component of PGA, PGV, PGD and 5\% damped linear elastic response spectra for periods ranging from 0.01 to $10 \mathrm{~s}$. Earthq Spectra 24(1):139-171

Campos Costa A, Sousa ML, Carvalho A, Coelho E (2006) Seismic loss scenarios based on hazard disaggregation. Application to the metropolitan region of Lisbon, Portugal. In: Oliviera CS, Goula X, Roca A (eds) Assessing and managing earthquake risk. Geo-scientific and engineering knowledge for earthquake risk mitigation: developments, tools, techniques, Springer, Netherlands, pp 449-46

Chiou BS-J, Youngs RR (2008) An NGA model for the average horizontal component of peak ground motion and response spectra. Earthq Spectra 24(1):173-215

Cox BR, Bachhuber J, Rathje E, Wood CM, Dulberg R, Kottke A, Green RA, Olson SM (2011) Shear wave velocity- and geology-based seismic microzonation of Port-au-Prince, Haiti. Earthq Spectra 27(S1):S67S92

Crowley H, Pinho R, Bommer JJ (2004) A probabilistic displacement-based vulnerability assessment procedure for earthquake loss estimation. Bull Earthq Eng 2(2):173-219

DeMets C, Jansma PE, Mattioli GS, Dixon TH, Farina F, Bilham R, Calais E, Mann P (2000) GPS geodetic constraints on Caribbean-North America plate motion. Geophys Res Lett 27:437-440

DesRoches R, Comerio M, Eberhard M, Mooney W, Rix GJ (2011) Overview of the 2010 Haiti earthquak. Earthq Spectra 27(S1):1-21. doi:10.1193/1.3630129

García-Jerez A, Luzón F, Navarro M, Pérez-Ruiz A (2006) Characterization of the sedimentary cover of the Zafarraya Basin, Southern Spain, by means of ambient noise. Bull Seismol Soc Am 96(3):957-967

Hayes GP, Briggs RW, Sladen A, Fielding EJ, Prentice C, Hudnut K, Mann P, Taylor F, Crone AJ, Gold R, Ito T, Simons M (2010) Complex rupture during the 12 January 2010 Haiti earthquake. Nat Geosci 3:800-805

Goodno BJ, Gould NC, Caldwell P, Gould PL (2011) Effects of the January 2010 Haitian earthquake on selected electrical equipment. Earthq Spectra 27(S1):251-276. doi:10.1193/1.3636415

FEMA (2008) HAZUS-MH Estimated Annualized Earthquake Losses for the United States (FEMA 366). Federal Emergency Management Agency, Washington, DC, USA, April 2008, 66 p

Holliday L, Grant H (2011) Haiti building failures and a replicable building design for improved earthquake safety. Earthq Spectra 27(S1):277-297. doi:10.1193/1.3636386

Lagomarsino S, Giovinazzi S (2006) Macroseismic and mechanical models for the vulnerability and damage assessment of current buildings. Bull Earthq Eng 4:415-443. doi:10.1007/s10518-006-9024-z

Lang A, Marshall J (2011) Devil in the details: success and failure of Haiti's nonengineered structures. Earthq Spectra 27(S1):S345-S372

Lang DH, Singh Y, Prasad JSR (2012) Comparing empirical and analytical estimates of earthquake loss assessment studies for the city of Dehradun, India. Earthq Spectra 28(2):595-619

Marshall J, Lang A, Baldridge S, Popp D (2011) Recipe for disaster: construction, methods, materials, and building performance in the January 2010 Haiti earthquake. Earthq Spectra 27(S1):S323-S343

McGuire RK (2004) Seismic hazard and risk analysis. EERI Publication No. MNO-10. Earthquake Engineering Research Institute, Oakland, CA, $221 \mathrm{p}$

Mix D., M, Kijewski-Correa T, Taflanidis AA (2011) Assessment of residential housing in Léogàne, Haiti, and identification of needs for rebuilding after the January 2010 earthquake. Earthq Spectra 27(S1):299-322. doi:10.1193/1.3637942

Molina S, Lang DH, Lindholm CD (2010) SELENA: an open-source tool for seismic risk and loss assessment using a logic tree computation procedure. Comput Geosci 36(2010):257-269

Nakamura Y (1989) A method for dynamic characteristics estimation of subsurface using microtremor on the ground surface. Q Rep Railw Tech Res Inst 30:25-33

NEHRP (2003) Recommended provisions for the development of seismic regulations for newbuildings. Building Seismic Safety Council, Washington, DC

O'Brien P, Eberhard M, Haraldsson O, Irfanoglu A, Lattanzi D, Lauer S, Pujol S (2011) Measures of the seismic vulnerability of reinforced concrete buildings in Haiti. Earthq Spectra 27(S1):373-386. doi:10. $1193 / 1.3637034$

Tokimatsu K (1997) Geotechnical site characterization using surface waves. In: Ishihara (ed) Earthquake geotechnical engineering. Balkema, Rótterdam, pp 1333-1368 